\title{
IMPLEMENTASI AUGMENTED REALITY UNTUK MEDIA INFORMASI BUAH LANGKA KHAS KALIMANTAN SELATAN
}

\author{
Yusri Ikhwani $^{1)}$, Mokhamad Ramdhani Raharjo ${ }^{2)}$ \\ ${ }^{1}$ Fakultas Teknologi Informasi, Universitas Islam Kalimantan Muhammad Arsyad Al Banjari Banjarmasin \\ Email : yusri.ikhwani@gmail.com \\ ${ }^{2}$ Fakultas Teknologi Informasi, Universitas Islam Kalimantan Muhammad Arsyad Al Banjari Banjarmasin \\ Email : 007.ramdhani@gmail.com
}

\begin{abstract}
Abstrak
Provinsi Kalimantan Selatan terdiri dari 11 Kabupaten dan 2 Kota. Dalam urusan buah-buahan, Secara geografis Kalimantan Selatan teletak di daerah tropis yang memungkinkan berbagai jenis tumbuhan dan buah-buahan dapat tumbuh subur. Keragaman aneka tumbuhan dan buah-buahan merupakan kekayaan alam yang harus dijaga, Provinsi Kalimantan Selatan sangat kaya akan jenis buah-buahan, salah satunya adalah buah kasturi. Ada banyak lagi jenis buah yang aneh dan sungguh sensasional, baik dari segi bentuk dan rasa. Augmented Reality (AR) adalah sebuah teknologi yang menggabungkan dunia virtual dengan dunia nyata, dimana pengguna dapat mengeksplor dunia nyata dengan lebih atraktif dan lebih menarik. Pemanfaatan teknologi AR banyak digunakan pada bidang edukasi, kesehatan, militer, iklan, hiburan dan navigasi. Umumnya aplikasi yang menggunakan teknologi AR bertujuan untuk memberikan informasi kepada pengguna dengan lebih jelas, real-time, dan interaktif. Pembuatan Augmented Reality ini bertujuan untuk mengenalkan, memberi pengetahuan, dan pemahaman tentang buah-buahan khas Kalimantan Selatan yang sudah mulai langka karena buah tersebut berada di hutan atau pedalaman kalimantan selatan kepada para masyarakat khususnya generasi muda yang sudah mulai melupakan buah-buah khas Kalimantan Selatan tersebut, dengan cara yang kreatif dan inovatif agar lebih menarik minat para generasi muda untuk mengenal buah langka tersebut. Pembuatan aplikasi Augmented Reality ini akan menggunakan Unity sebagai komponen utama ditambah library Augmented Reality terbaru yaitu Vuforia. Kemudian menggunakan Blender 3D sebagai software perancang model objek. Implementasi teknologi Augmented Reality dalam pembuatan aplikasi berbasis Android ini dapat memberikan informasi kepada masyarakat tentang pengenalan berbagai jenis buah-buahan yang ditampilkan dalam bentuk 3D.
\end{abstract}

Kata kunci: Kalimantan, Buah, Langka, Augmented Reality, Informasi, 3D

\section{PENDAHULUAN}

Secara geografis Indonesia teletak di daerah tropis yang memungkinkan berbagai jenis tumbuhan dan buah-buahan dapat tumbuh subur. Keragaman aneka tumbuhan dan buahbuahan merupakan kekayaan alam yang harus dijaga. Kalimantan Selatan adalah salah satu provinsi di Indonesia yang terletak di pulau Kalimantan dengan Banjarmasin sebagai ibu kotanya. Provinsi Kalimantan Selatan yang terdiri dari 11 Kabupaten dan 2 Kota. Dalam urusan buah-buahan, Provinsi Kalimantan Selatan sangat kaya akan jenis buah-buahan, salah satunya adalah buah kasturi. Ada banyak lagi jenis buah yang aneh dan sungguh sensasional, baik dari segi bentuk dan rasa.

Kemajuan di bidang komputerisasi yang sangat berkembang dapat dijadikan salah satu alternatif dalam mengenalkan buah-buahan langka khas Kalimantan Selatan kepada masyarakat khususnya generasi muda. Terobosan teknologi terbaru misalnya Augmented Reality khususnya pada perangkat mobile (telepon genggam dan tablet) memang masih tergolong minim. Penggunaan AR saat ini telah melebar kebanyak aspek di dalam 
kehidupan kita dan diproyeksikan akan mengalami perkembangan yang signifikan. Augmented Reality (AR) adalah sebuah teknologi yang menggabungkan dunia virtual dengan dunia nyata, dimana pengguna dapat mengeksplor dunia nyata dengan lebih atraktif dan lebih menarik. Pemanfaatan teknologi AR banyak digunakan pada bidang edukasi, kesehatan, militer, iklan, hiburan dan navigasi. Umumnya aplikasi yang menggunakan teknologi AR bertujuan untuk memberikan informasi kepada pengguna dengan lebih jelas, real-time, dan interaktif.

Pembuatan Augmented Reality ini bertujuan untuk mengenalkan, memberi pengetahuan, dan pemahaman tentang buahbuahan khas Kalimantan Selatan yang sudah mulai langka karena buah tersebut berada di hutan atau pedalaman kalimantan selatan kepada para masyarakat khususnya generasi muda yang sudah mulai melupakan buah-buah khas Kalimantan Selatan tersebut, dengan cara yang kreatif dan inovatif agar lebih menarik minat para generasi muda untuk mengenal buah langka tersebut. Pembuatan aplikasi Augmented Reality ini akan menggunakan Unity sebagai komponen utama ditambah library Augmented Reality terbaru yaitu Vuforia. Kemudian menggunakan Blender 3D sebagai software perancang model objek. Implementasi teknologi Augmented Reality dalam pembuatan aplikasi berbasis Android ini dapat memberikan informasi kepada masyarakat tentang pengenalan berbagai jenis buah-buahan yang ditampilkan dalam bentuk 3D.

\section{METODE PENELITIAN}

Tahapan yang digunakan dalam penelitian ini sebagai berikut :

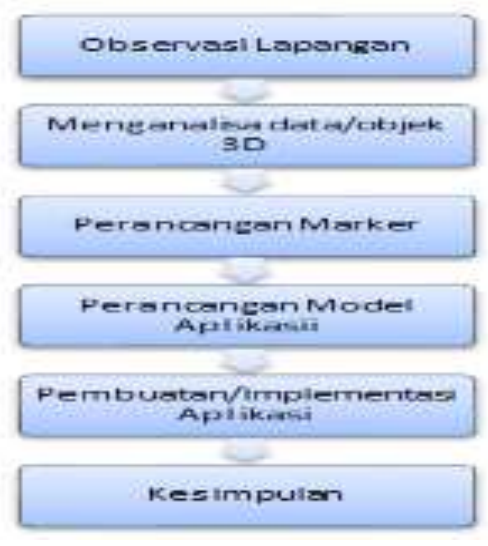

Jurnal Ilmiah “Technologia"
1. Observasi lapangan untuk menganalisa data

2. Menganalisa data dengan menggunakan metode marker based tracking sebagai penanda untuk menjadikan tampilkan objek 3D.

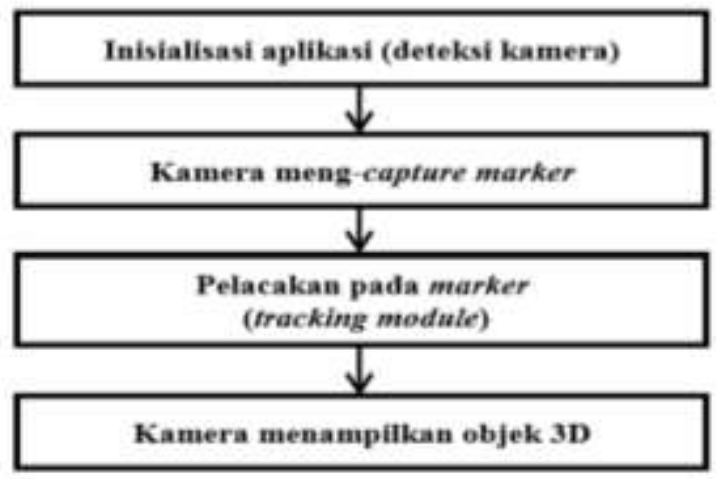

3. Perancangan Marker

Marker merupakan komponen inti dari penelitian ini karena metode marker based tracking merupakan tipe augmented reality yang mengenali marker dan mengidentifikasi pola dari marker tersebut untuk menambahkan suatu objek virtual ke lingkungan nyata.

4. Perancangan Model Sistem/Aplikasi

Rancangan model sistem menggambarkan tentang kebutuhan sistem yang akan dibangun.

5. Implementasi dan Pengujian Sistem

6. Menarik kesimpulan

\section{HASIL DAN PEMBAHASAN}

\subsection{Pengumpulan Data}

Proses pengumpulan data pada penelitian ini menganalisa data hasil observasi lapangan mengenai buah langka khas kalimantan selatan, yang terdiri dari buah kasturi, buah kapul dan buah lahung

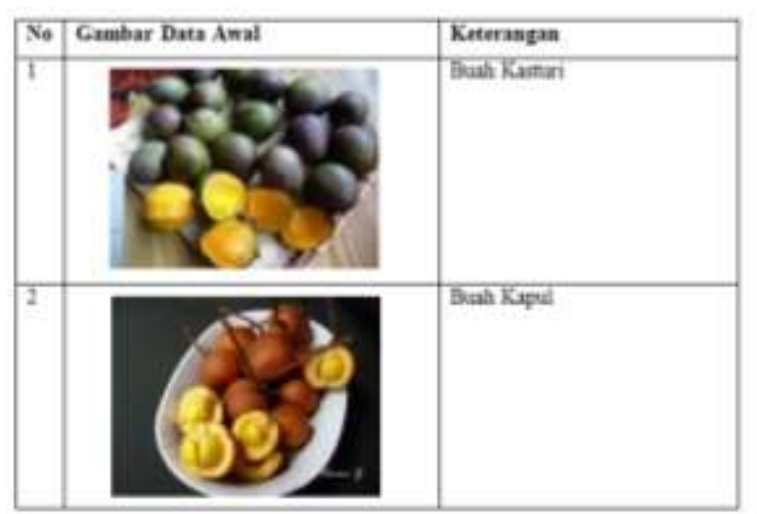




\subsection{Perancangan Marker}

Marker memiliki peranan penting pada sebuah aplikasi augmented reality karena berfungsi menampilkan objek 3D pada aplikasi augmented reality
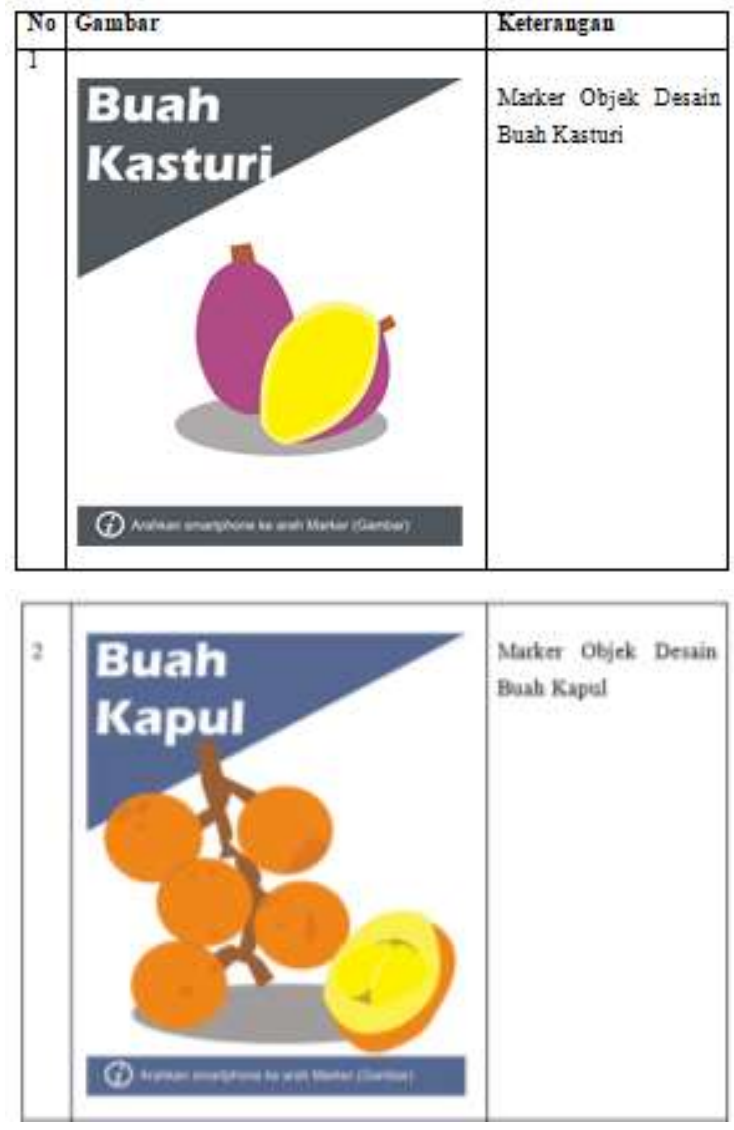

\subsection{Perancangan dan Implementasi}

Pengimplementasian aplikasi augmented reality sebagai media informasi buah langka yang berasal dari pedalaman Kalimantan Selatan yang mana dapat digunakan dengan komputer dan smartphone.

1. Form Pembuka

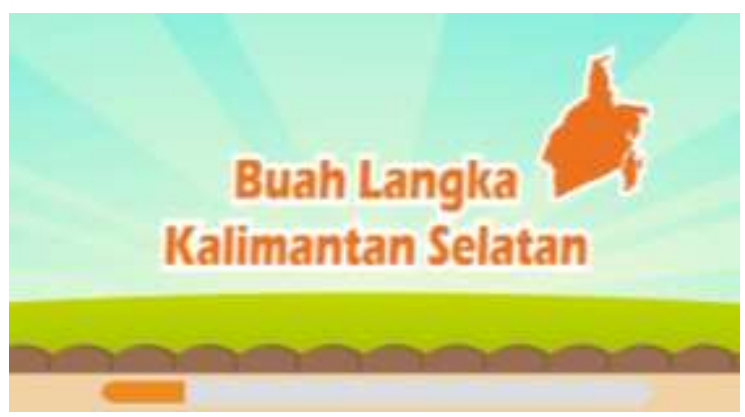

2. Form Menu Utama

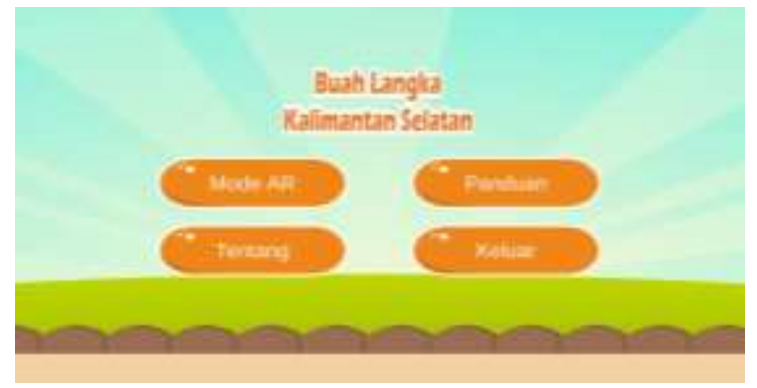

3. Form Mode AR Buah Kasturi

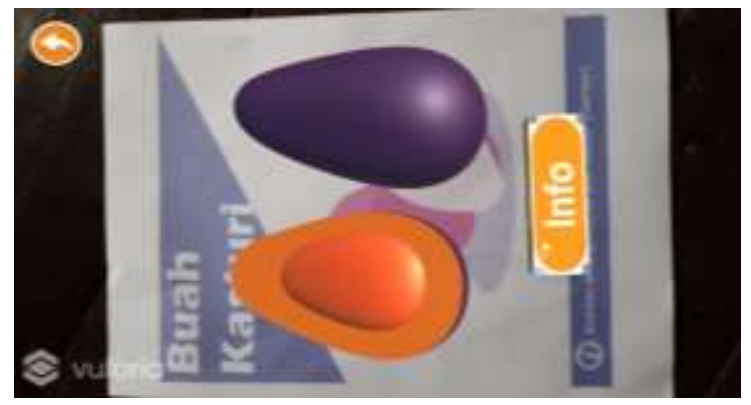

4. Form Mode AR Buah Kasturi \&Informasi

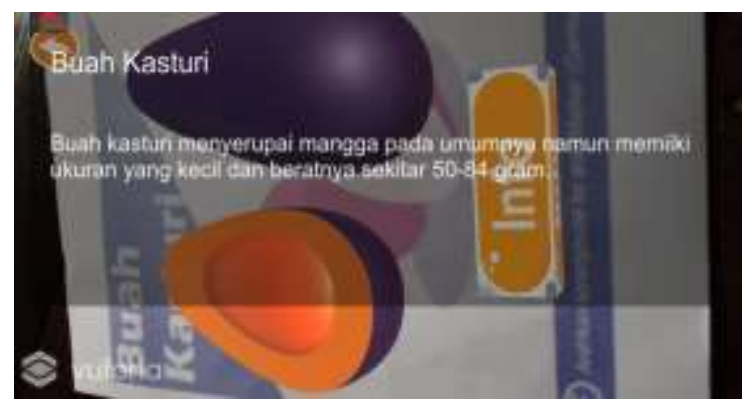

5. Form Mode AR Buah Kapul

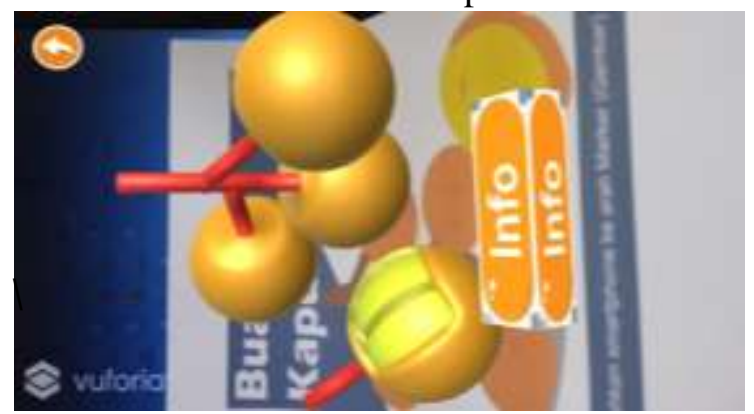

6. Form Mode AR Buah Kapul dan Informasi

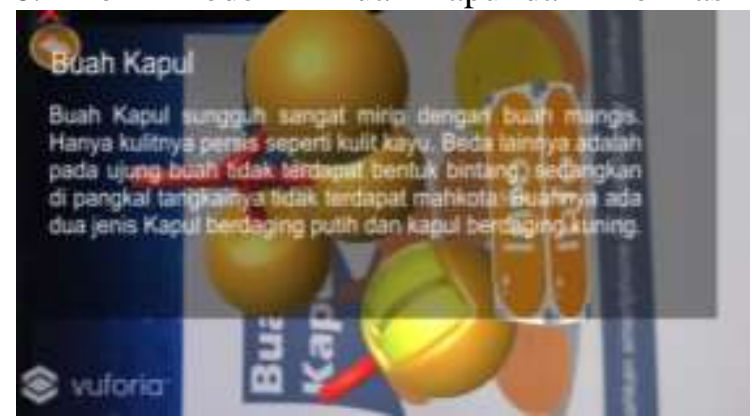




\subsection{Pengujian}

\begin{tabular}{|c|c|c|c|}
\hline No & $\begin{array}{l}\text { Pengujian } \\
\text { Marker } \\
\text { Buah } \\
\text { Kasturi } \\
\end{array}$ & $\begin{array}{c}\text { Jarak } \\
\text { dan } \\
\text { Sudut }\end{array}$ & Keterangan \\
\hline 1 & Memindai & $\begin{array}{c}20 \mathrm{~cm}- \\
30^{\circ}\end{array}$ & $\begin{array}{l}\text { Berhasil } \\
\text { Menampilkan Objek } \\
\text { 3D Buah Kasturi }\end{array}$ \\
\hline 2 & Memindai & $\begin{array}{c}20 \mathrm{~cm}- \\
60^{\circ}\end{array}$ & $\begin{array}{l}\text { Berhasil } \\
\text { Menampilkan Objek } \\
\text { 3D Buah Kasturi }\end{array}$ \\
\hline 3 & Memindai & $\begin{array}{c}20 \mathrm{~cm}- \\
90^{\circ}\end{array}$ & $\begin{array}{l}\text { Berhasil } \\
\text { Menampilkan Objek } \\
\text { 3D Buah Kasturi } \\
\end{array}$ \\
\hline 4 & Memindai & $\begin{array}{c}25 \mathrm{~cm}- \\
30^{\circ}\end{array}$ & $\begin{array}{l}\text { Berhasil } \\
\text { Menampilkan Objek } \\
\text { 3D Buah Kasturi }\end{array}$ \\
\hline 5 & Memindai & $\begin{array}{c}25 \mathrm{~cm}- \\
60^{\circ}\end{array}$ & $\begin{array}{l}\text { Berhasil } \\
\text { Menampilkan Objek } \\
\text { 3D Buah Kasturi }\end{array}$ \\
\hline 6 & Memindai & $\begin{array}{c}25 \mathrm{~cm}- \\
90^{\circ}\end{array}$ & $\begin{array}{l}\text { Berhasil } \\
\text { Menampilkan Objek } \\
\text { 3D Buah Kasturi } \\
\end{array}$ \\
\hline 7 & Memindai & $\begin{array}{c}30 \mathrm{~cm}- \\
30^{\circ}\end{array}$ & $\begin{array}{l}\text { Berhasil } \\
\text { Menampilkan Objek } \\
\text { 3D Buah Kasturi }\end{array}$ \\
\hline 8 & Memindai & $\begin{array}{c}30 \mathrm{~cm}- \\
60^{\circ}\end{array}$ & $\begin{array}{l}\text { Berhasil } \\
\text { Menampilkan Objek } \\
\text { 3D Buah Kasturi }\end{array}$ \\
\hline 9 & Memindai & $\begin{array}{c}30 \mathrm{~cm}- \\
90^{\circ}\end{array}$ & $\begin{array}{l}\text { Berhasil } \\
\text { Menampilkan Objek } \\
\text { 3D Buah Kasturi }\end{array}$ \\
\hline No & $\begin{array}{c}\text { Pengujian } \\
\text { Marker } \\
\text { Buah Kapul }\end{array}$ & $\begin{array}{c}\text { Jarak } \\
\text { dan } \\
\text { Sudut }\end{array}$ & Keterangan \\
\hline 1 & Memindai & $\begin{array}{c}20 \mathrm{~cm}- \\
30^{\circ}\end{array}$ & $\begin{array}{l}\text { Berhasil } \\
\text { Menampilkan Objek } \\
\text { 3D Buah Kapul }\end{array}$ \\
\hline 2 & Memindai & $\begin{array}{c}20 \mathrm{~cm}- \\
60^{\circ}\end{array}$ & $\begin{array}{l}\text { Berhasil } \\
\text { Menampilkan Objek } \\
\text { 3D Buah Kapul }\end{array}$ \\
\hline 3 & Memindai & $\begin{array}{c}20 \mathrm{~cm}- \\
90^{\circ}\end{array}$ & $\begin{array}{l}\text { Berhasil } \\
\text { Menampilkan Objek } \\
\text { 3D Buah Kapul }\end{array}$ \\
\hline 4 & Memindai & $\begin{array}{c}25 \mathrm{~cm} \mathrm{-} \\
30^{\circ}\end{array}$ & $\begin{array}{l}\text { Berhasil } \\
\text { Menampilkan Objek } \\
\text { 3D Buah Kapul }\end{array}$ \\
\hline 5 & Memindai & $\begin{array}{c}25 \mathrm{~cm}- \\
60^{\circ}\end{array}$ & $\begin{array}{l}\text { Berhasil } \\
\text { Menampilkan Objek } \\
\text { 3D Buah Kapul }\end{array}$ \\
\hline 6 & Memindai & $\begin{array}{c}25 \mathrm{~cm}- \\
90^{\circ}\end{array}$ & $\begin{array}{l}\text { Berhasil } \\
\text { Menampilkan Objek } \\
\text { 3D Buah Kapul } \\
\end{array}$ \\
\hline 7 & Memindai & $\begin{array}{c}30 \mathrm{~cm}- \\
30^{\circ}\end{array}$ & $\begin{array}{l}\text { Berhasil } \\
\text { Menampilkan Objek } \\
\text { 3D Buah Kapul } \\
\end{array}$ \\
\hline 8 & Memindai & $\begin{array}{c}30 \mathrm{~cm}- \\
60^{\circ}\end{array}$ & $\begin{array}{l}\text { Berhasil } \\
\text { Menampilkan Objek } \\
\text { 3D Buah Kapul }\end{array}$ \\
\hline 9 & Memindai & $\begin{array}{c}30 \mathrm{~cm}- \\
90^{\circ}\end{array}$ & $\begin{array}{l}\text { Berhasil } \\
\text { Menampilkan Objek } \\
\text { 3D Buah Kapul }\end{array}$ \\
\hline
\end{tabular}

\section{KESIMPULAN}

Kesimpulan dari hasil penelitian ini sebagai berikut:

1. Aplikasi AR untuk media informasi buah langka khas Kalimantan Selatan dapat memberikan wawasan dan sebagai media pembelajaran dengan objek 3D.

2. Aplikasi AR dapat Mengenalkan, memberi pengetahuan, dan pemahaman tentang buah-buahan khas Kalimantan Selatan dengan cara kreatif dan inovatif.

\section{DAFTAR PUSTAKA}

[1] Azuma, R. T. (2001). Indirect Augmented Reality. Nokia Research Cencer Hollywood United States.

[2] Andriyadi, A. (2011). Augmented reality with ARToolkit. Lampung: Augmented reality Team.

[3] Atmoko Nugroho, B. A. ( Januari 2017). Aplikasi Mobile Augmented Reality Berbasis Vuforia Dan Unity Pada Pengenalan Objek 3d Dengan Studi Kasus Gedung M Universitas Semarang. Jurnal Transformatika, 84-91.

[4] A. Pramono and M. D. Setiawan, "Pemanfaatan Augmented Reality Sebagai Media Pembelajaran Pengenalan Buah-Buahan," no. 1 Februari, 2019

[5] M. R. Mubaraq, H. Kurniawan, and Alfa Saleh, "Implementasi Augmented Reality Pada Media Pembelajaran Buahbuahan Berbasis Android" ,IT Journal, Vol. 6 No. 1, April, 2018

[6] M. B. Rahmat, "Pengembangan Aplikasi Pengenalan Buah-Buahan Khas Indonesia Menggunakan Teknologi Augmented Reality Berbasis Android" Desember 2018

[7] P. A. Hadi "Perancangan Aplikasi Informasi Multimedia Tanaman Buah Kebun Bogor Dengan Augmented Reality", Narada, Jurnal Desain \& Seni, FDSK - UMB, 445

[8] A. Syahrin, M. E. Apriyani, S. Prasetyaningsih, "Analisis Dan Implementasi Metodemarker Based Tracking Pada Augmented Reality Pembelajaran Buah-Buahan", Komputa, Vol 5, No.1, Maret, 2016 